\title{
Raman analysis of ancient pigments on a tile from the Citadel of Algiers ${ }^{\text {is }}$
}

\author{
L.D. Kock*, D. De Waal \\ Department of Chemistry, University of Pretoria, Pretoria 0002, South Africa
}

\section{A R T I C L E I N F O}

\section{Article history:}

Received 23 June 2007

Received in revised form 16 February 2008

Accepted 16 April 2008

\section{Keywords:}

Raman microscopy

Pigments

Citadel of Algiers

Tile shard

\begin{abstract}
A B S T R A C T
A micro-Raman spectroscopy study of a multi-coloured (yellow, blue, white, redish-brown and brownblack) tile shard from the Citadel of Algiers was undertaken. XRD and EDX were used as complementary techniques. The study shows that the heterogeneous three-shade yellow pigment on the tile is composed largely of the ancient ternary $(\mathrm{Pb}-\mathrm{Sn}-\mathrm{Sb})$ pyrochlore oxide with a dominant $\mathrm{Pb}-\mathrm{O}$ vibration at $127 \mathrm{~cm}^{-1}$ consistent with the $\mathrm{Pb}_{2} \mathrm{SnSbO}_{6.5}$ structure as verified by XRD. The literature assignment of this band at $132 \mathrm{~cm}^{-1}$ probably comes from a mixture of pigments. The redish-brown and the brown-black pigments are found to be Naples yellow $\left(\mathrm{Pb}_{2} \mathrm{Sb}_{2} \mathrm{O}_{7}\right)$ and lead(II) stannate $\left(\mathrm{Pb}_{2} \mathrm{SnO}_{4}\right)$, respectively, while cobalt blue $\left(\mathrm{CoAl}_{2} \mathrm{O}_{4}\right)$ gives the blue colour and cassiterite $\left(\mathrm{SnO}_{2}\right)$ is the origin of the white colour. The bulk of the tile body is composed mainly of hematite $\left(\alpha-\mathrm{Fe}_{2} \mathrm{O}_{3}\right)$, maghemite $\left(\gamma-\mathrm{Fe}_{2} \mathrm{O}_{3}\right)$, magnetite $\left(\mathrm{Fe}_{3} \mathrm{O}_{4}\right)$ and Quartz $\left(\alpha-\mathrm{SiO}_{2}\right)$ with traces of calcite $\left(\mathrm{CaCO}_{3}\right)$ and amorphous carbon. Micro-Raman spectroscopy proved to be very useful in the characterization of pigments as well as the tile body. These results further establish Raman spectroscopy as a technique of choice for the analysis of pigments on archaeological artifacts. The results obtained here could be used in the restoration and preservation programme of the Citadel itself which stands today as a symbol of pre-colonial Algerian heritage.
\end{abstract}

(C) 2008 Elsevier B.V. All rights reserved.

\section{Introduction}

The success of Raman microscopy in the study of pigments on artworks has already been proven [1-3]. This non-destructive technique has also been applied to pigments on painted pottery [4], ceramic shards [5,6], paint fragments from frescoes and wall paintings [7,8], manuscripts [9], including pigment mixtures [10]. Pigments on post-mediaeval glazed tiles [11] and components of archaeological tile samples dating from the Ming period [12] have also been probed using Raman microscopy. The ability to probe pigments in the glaze interior of artifacts and tiles by glaze depth profiling makes micro-Raman spectroscopy a valuable tool in the study of pigments on glazed artifacts. Very often, intimate knowledge of these pigments is necessary for purposes of authentication, restoration and conservation of ancient artworks and artifacts $[13,14]$ and glaze depth profiling provides another avenue by which these can be identified on artworks and artifacts [15].

The versatility of Raman microscopy in the study of pigments has lead to the development of several useful pigment and mineral spectral databases [16-18] that are made available to assist in

\footnotetext{
is Contract/grant sponsors: University of Pretoria and National Research Foundation.

* Corresponding author. Fax: +27 123625297.

E-mail address: david.kock@up.ac.za (L.D. Kock)
}

Raman band assignments and the subsequent identification of the pigments and minerals. The identification of artificial pigments on artworks and artifacts also play a major role in their authentication based in part on the history and first use of the pigments in question $[3,19]$. In addition, the quality and elaborate collection of materials used by the painters can also highlight the artistic value of the artwork under study [20]. In this communication, the results of a micro-Raman study on a glazed multi-coloured tile obtained from the Citadel of Algiers are presented. The pigments on this tile were probed by focusing on the pigment grains where these were exposed on the surface, and by a systematic process of glaze depth profiling using a long focal length $50 \times$ objective lens (Olympus) on the microscope. A vertical step-wise interval of $4 \mu \mathrm{m}$ was used in order to generate the vertical glaze depth profile. The spectral results were then compared and contrasted to known pigments. Various reference compounds were also synthesized and analysed to aid in the identification of the various pigments.

\section{Experimental}

\subsection{Sample}

The tile piece came from the Citadel of Algiers located just above the Medina of El Dzezair. The Citadel itself was constructed in 1516 on the instruction of Dey Aroudj Barbarossa and later enlarged by Mustapha Pasha. At the arrival of the Dey Hussein 
as head of government, the Citadel was rearranged in terms of its new function - that of seat of administration, justice and finance. It then consisted of several palaces and apartments, mosques, bunkers, several outbuildings reserved for regional rulers and in addition, a gun powder room which served as a factory for the manufacturing of saltpeter. This gun powder room stands today as the only architectural example of its kind in Algeria. Currently the Citadel is ear-marked for restoration and development into a symbol of pre-colonial Algerian heritage. The tile piece from the Citadel is multi-coloured with decorations in yellow, redish-brown, brown-black, blue and white (Plate $1)$.

The cobalt aluminium oxide $\left(\mathrm{CoAl}_{2} \mathrm{O}_{4}\right)$ was synthesized in this laboratory [21]. The lead(II) stannate also called lead tin yellow type I $\left(\mathrm{Pb}_{2} \mathrm{SnO}_{4}\right)$, lead(II) antimonite also called Naples yellow $\left(\mathrm{Pb}_{2} \mathrm{Sb}_{2} \mathrm{O}_{7}\right)$ and a ternary compound $\left(\mathrm{Pb}_{2} \mathrm{SnSbO}_{6.5}\right)$ was synthesized in this laboratory using literature methods [22,23]. The $\mathrm{SnO}_{2}$, $\mathrm{PbO}$ and $\mathrm{Sb}_{2} \mathrm{O}_{3}$ references were used as received (Merck, Johannesburg, South Africa).

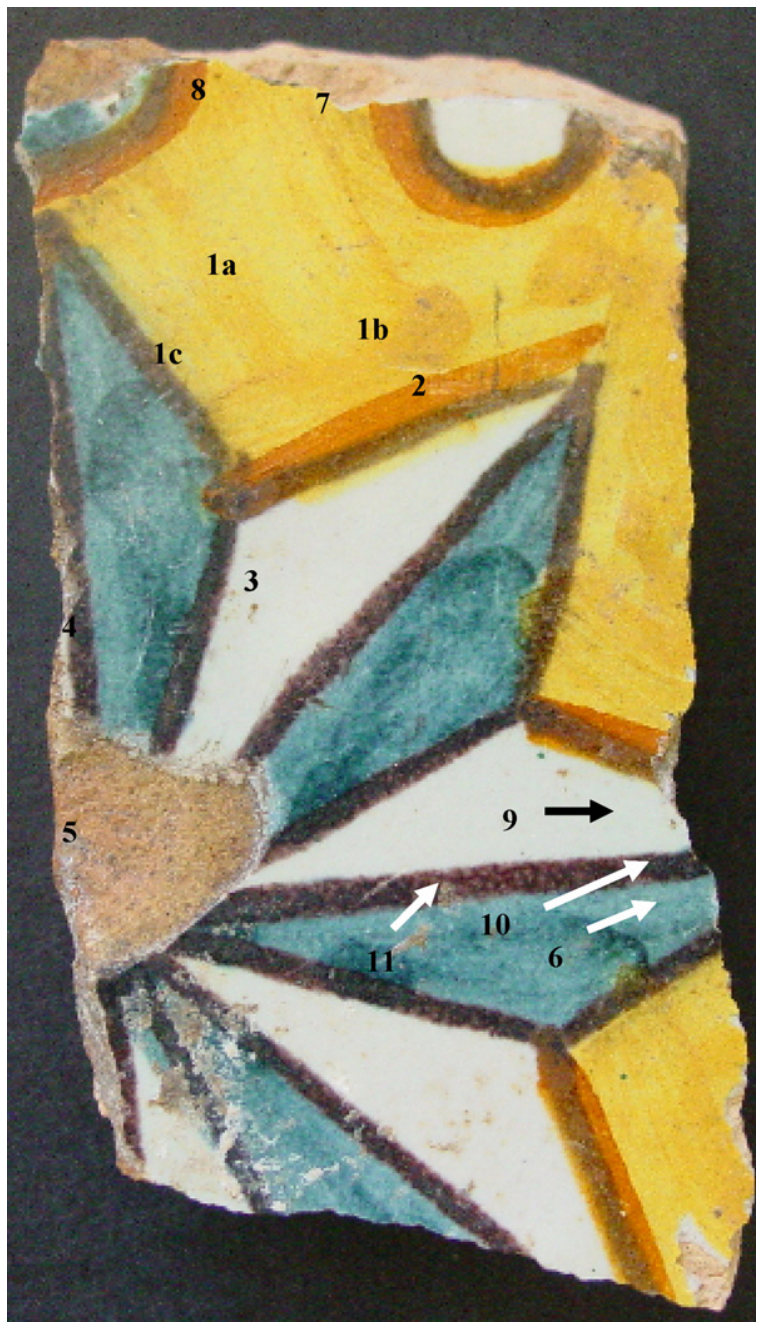

Plate 1. The front of the tile showing the various colours. The numbered areas indicate positions where representative Raman spectra were obtained: (1) yellow ((1a) bright-yellow, (1b) orange-yellow, (1c) brownish-yellow), (2) reddish-brown, (3) white, (4) blue, (5) tile body, (6) blue/glaze/body as shown edge-on in Plate 3(a), (7) reddish-brown/glaze/body as shown edge-on in Plate 3(b), (8) yellow/glaze/body as shown edge-on in Plate 2(a), (9) white/glaze/body (Plate 2(b)), (10) brownblack/glaze/body (Plate 3(c)) and (11) brown-black surface.

\subsection{Raman measurements}

Raman spectra were acquired with a Dilor XY multi-channel spectrometer equipped with a liquid nitrogen-cooled CCD detector. A back-scattering $\left(180^{\circ}\right)$ micro-Raman configuration using an Olympus confocal microscope (Model BHT) was used. The instrument was calibrated against the $520.7 \mathrm{~cm}^{-1}$ Silicon line on a daily basis. The excitation radiation was provided by $\mathrm{Kr}^{+}$and $\mathrm{Ar}^{+}$ lasers operating at 568.2 and $514.5 \mathrm{~nm}$ wavelengths, respectively. The laser powers were set at ca. $5 \mathrm{~mW}\left(\mathrm{Kr}^{+}\right)$and $20 \mathrm{~mW}\left(\mathrm{Ar}^{+}\right)$ as measured at the source. The power at the sample for pigment grain studies were set typically at between 0.5 and $2 \mathrm{~mW}$ to prevent sample degradation $[24,25]$. This power was adjusted upwards when glaze depth profiles were generated and focusing was done inside the glaze. Integration times typically depended on the type of sample and were between 10 and $300 \mathrm{~s}$. Integration times were set at between 120 and 300 s with 3 accumulations for the glaze spectra. Laser power settings were adjusted lower (5-10 $\mathrm{mW}$ on the $\mathrm{Ar}^{+}$at source) for the tile body analysis to avoid sample degradation. Data acquisition and processing were carried out with Labspec ${ }^{\circledR}$ software [26] version 3.01 (Jobyn Yvon, Horiba Group) and an Olympus camera (Camedia C-7070WZ) mounted on top of the microscope by means of an Olympus NFK eyepiece was used to capture the images. The long focal length $50 \times$ objective lens (Olympus) was used to generate the glaze depth profiles.

\section{3. $X R D$ and EDX measurements}

X-ray diffraction (XRD) measurements were used to verify the crystal structures of the synthesized pigments and a Siemens D$501 \mathrm{X}$-ray powder diffractometer using $\mathrm{Cu} \mathrm{K} \alpha$ radiation was used for that purpose. The applied potential and corresponding current were $40 \mathrm{kV}$ and $40 \mathrm{~mA}$, respectively, and the $2 \theta$ values were measured from $10^{\circ}$ to $70^{\circ}$ for all recordings [27]. The verification of the presence and/or absence of elements in the various pigments on the Citadel tile were accomplished with energy dispersive X-ray spectrometry measurements. A JEOL JSM-5800LV scanning electron microscope was used for the EDX measurements. The use of low vacuum in these studies obviated the use of gold sputtering and the sample was therefore used as received. $\chi^{2}$ values ranged between 1.3 and 1.6 for all EDX measurements.

\section{Results and discussion}

\subsection{Microstructure}

Plate 2 shows optical micrographs of the surface/glaze/body layers at the (a) yellow and (b) white pigment background sections while Plate 3 shows (a) blue, (b) redish-brown and (c) black-brown pigment background sections of the shard as obtained edge-on. The white glaze is clearly shown with sparkles resembling luster type glazes that usually contain silver and/or copper in the metallic and ionic form giving shimmering surfaces that can change colour as a result of optical interferences [28]. The glaze is about $300-400 \mu \mathrm{m}$ thick while the yellow pigment section is about $30-40 \mu \mathrm{m}$ thick. Beyond the glaze in the tile body, particles of various sizes, shapes and colours are visible under the microscope (Plate $2(\mathrm{a}(1)$ and $\mathrm{b}(6)$ ). The microstructure of the tile body appears more heterogeneous than the tile glaze (Plate 2(a(2)). Raman microscopy has shown that while the glaze is composed mostly of $\mathrm{SnO}_{2}$ interspersed with $\alpha$-quartz, the tile body contains iron oxides (hematite, maghemite and magnetite), $\alpha$-quartz, amorphous carbon and calcite as distinct components in the redish/brown tile body. These components are 
(a)

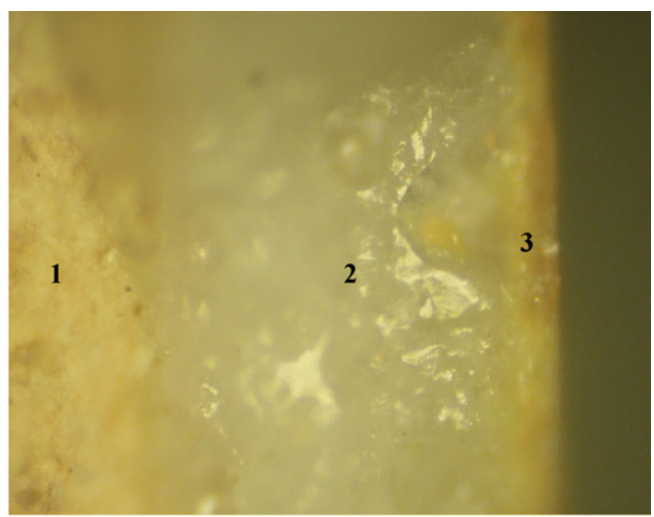

(b)

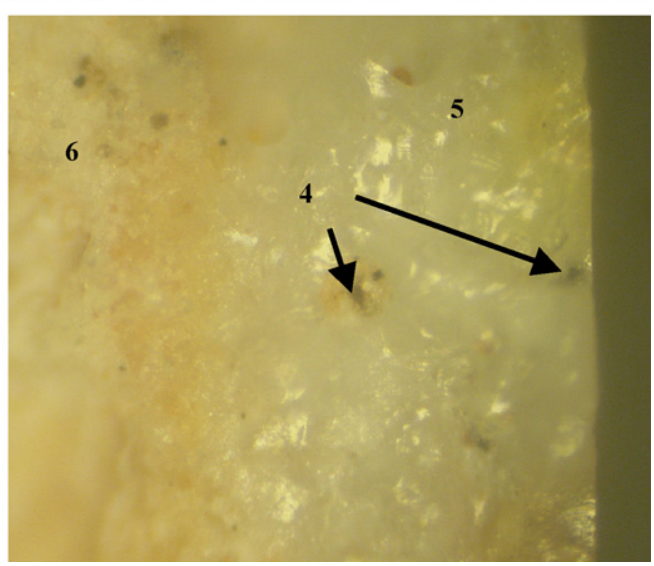

Plate 2. This plate shows the surface/glaze/body interfaces for (a) yellow pigment background and (b) the white pigment background. The different components shown are: (1 and 6) tile body, (2) glaze, (3) yellow pigment on the surface, (4) some black inclusions some of which are shown to be amorphous carbon particles and (5) glaze on white background. The micrographs were captured with an Olympus camera (Camedia C7070WZ) using 50× (500 times magnification) objective lens.

discussed separately under the heading 'Tile body analysis' in this manuscript.

\subsection{Identified pigment}

\subsubsection{Yellow pigments}

On careful observation under the microscope, the yellow pigment on this tile appeared to have different shades of yellow that can be described qualitatively as bright-yellow, orange-yellow and brownish-yellow. Fig. 1(a-c) shows spectra collected from the different shades with Fig. 1(a) corresponding to bright-yellow, (b) orange-yellow and (c) brownish-yellow using the $568.2 \mathrm{~nm}$ excitation with $3 \mathrm{~mW}$ laser power at the source. This general trend was also established using the $514.5 \mathrm{~nm}$ excitation beam with $20 \mathrm{~mW}$ laser power at the source (Fig. $2(\mathrm{a}-\mathrm{c})$ ). A common feature among the these spectra is the differences in relative intensity of the dominant Raman bands in the $127-145 \mathrm{~cm}^{-1}$ range in addition to corresponding shifts in the band around $506-510 \mathrm{~cm}^{-1}$. Clearly the dominance of the $137 \mathrm{~cm}^{-1}$ Raman band relative to the $127 \mathrm{~cm}^{-1}$ band is accompanied by the shift of the $510 \mathrm{~cm}^{-1}$ band to lower wavenumbers $\left(506 \mathrm{~cm}^{-1}\right)$ with a corresponding colour change in the yellow pigment from brownish-yellow to bright-yellow or orange-yellow (where both Raman bands are of about the same intensity) as illustrated in Fig. 3. The bright yellow pigment is illustrated in Fig. 3 by a mid-point value between 127 and $137 \mathrm{~cm}^{-1}$.

Lead based yellow pigments have been in use since antiquity [23]. The most common of these yellow pigments have a common dominant Raman band at ca. $127-145 \mathrm{~cm}^{-1}$ and differ from each (a)

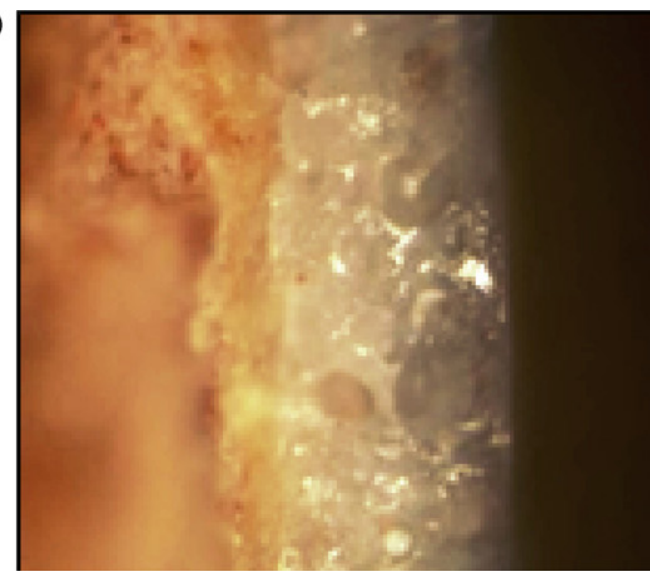

(b)

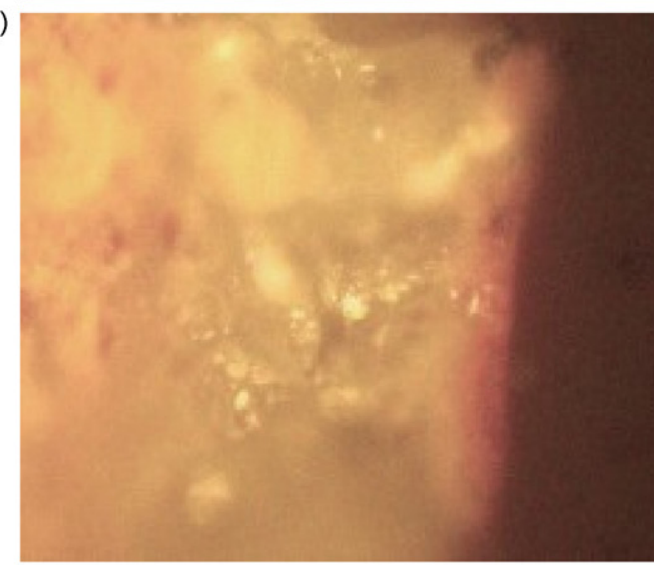

(c)

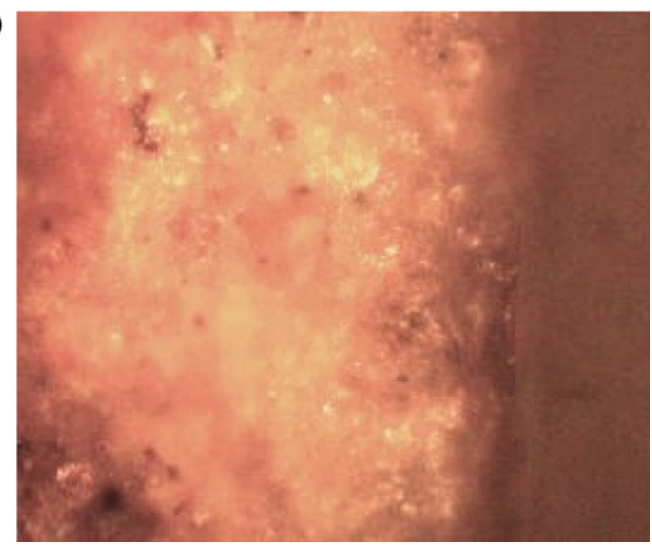

Plate 3. The surface/glaze/body interfaces for the (a) blue, (b) redish-brown and (c) black-brown pigment background sections captured through a $10 \times(100$ times magnification) objective lens using an Olympus camera (Camedia C7070WZ) mounted on top of the microscope (Olympus).

other by the position of this dominant band (DB) that has been attributed to a lattice $\mathrm{Pb}-\mathrm{O}$ stretching mode [23]. (Note that in the case of the yellow pigment on the tile, shifts in the Raman band at $506 \mathrm{~cm}^{-1}$ is also observed.) In this historical group of yellow pigments the following can be distinguished: lead tin yellow (Type I (DB at 129 (vs) and $196 \mathrm{~cm}^{-1}$ (s)) and Type II (DB at 138 (vs) and broad bands at $324 \mathrm{~cm}^{-1}(\mathrm{~m})$ ), lead(II) antimonate often called Naples yellow (DB at $140 \mathrm{~cm}^{-1}$ and broad bands at $329 \mathrm{~cm}^{-1}(\mathrm{~m})$ and $442 \mathrm{~cm}^{-1}(\mathrm{w})$ ), two lead (II) oxides (orthorhombic $\left(143 \mathrm{~cm}^{-1}\right.$ (vs), $289 \mathrm{~cm}^{-1}(\mathrm{~s})$ and $\left.385 \mathrm{~cm}^{-1}(\mathrm{w})\right)$ and tetragonal $\left(145 \mathrm{~cm}^{-1}(\mathrm{vs})\right.$, $285 \mathrm{~cm}^{-1}$ (vw) and $336 \mathrm{~cm}^{-1}$ (vw)) crystals [22].

The Raman spectra of the yellow pigment on the tile from the Citadel of Algiers do not match any of these common yellow pig- 


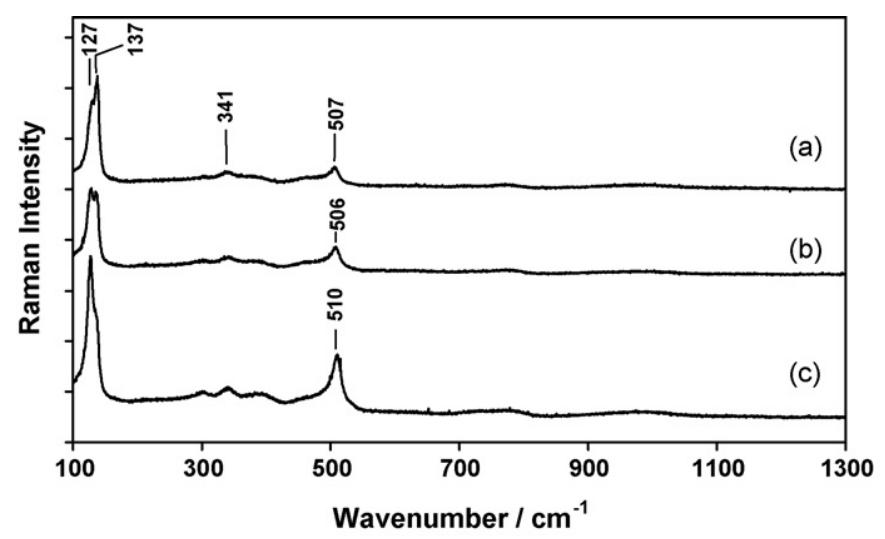

Fig. 1. All three spectra were collected from the yellow background on the tile using $568.2 \mathrm{~nm}$ radiation ( $3 \mathrm{~mW}$ laser power at the source). (a) bright yellow, (b) orangeyellow and (c) brownish yellow. Similar results are obtained with $514.5 \mathrm{~nm}$ radiation with $20 \mathrm{~mW}$ laser power as measured at the source.

ments. Rather, Raman spectra indicates that it is similar to the ancient yellow ternary $(\mathrm{Pb}-\mathrm{Sn}-\mathrm{Sb})$ pigment whose formulation was described as $\mathrm{Pb}_{2} \mathrm{SnSbO}_{6.5}$ [26] and was later identified on Italian paintings "Lot and his daughters" by G.B. Langetti and "Entrance of Christ in Jerusalem" by Luca Giordano [29] as well as Italian pottery of the sixteenth century [30]. The yellow pigment on the tile appears to be a heterogeneous mixture of bright and darker shades of yellow, which in turn may reflect a heterogeneous pigment mixture, which may be of various structural forms. This rediscovered ancient yellow pigment has been reported as mixtures of a cubic pyrochlore type structure (space group F d3m (No. 227), $Z=8$ ) with significant amounts of lead(II) antimonate $\left(\mathrm{Pb}_{2} \mathrm{Sb}_{2} \mathrm{O}_{7}\right)$ oxide depending on the ratios of the starting material during manufacture [31]. The largest proportion of the pyrochlore being obtained when the molar ratio of the base oxide $(\mathrm{Pb}: \mathrm{Sn}: \mathrm{Sb})$ are $2: 1: 1$ accompanied by a negligible amount of $\mathrm{SnO}_{2}[31,32]$. Increasing the antimony oxide to $\mathrm{Sn}: \mathrm{Sb}=1: 2$ molar ratios results in the larger quantities of the hexagonal structure $\left(\mathrm{PbSb}_{2} \mathrm{O}_{6}\right)$ in addition to the pyrochlore type ternary pigment [31,32].

Fig. 4(a-c) shows the spectrum of the yellow pigment from Citadel shard and Fig. 4(e) is the reference Raman spectrum of the ternary $(\mathrm{Pb}-\mathrm{Sn}-\mathrm{Sb})$ type pyrochlore yellow pigment prepared in this laboratory according to methods that were described elsewhere [31]. Clearly the pigment obtained from the Citadel shard is a mixture of pigments and/or $\mathrm{Pb}-\mathrm{O}$ bond length types indicated by

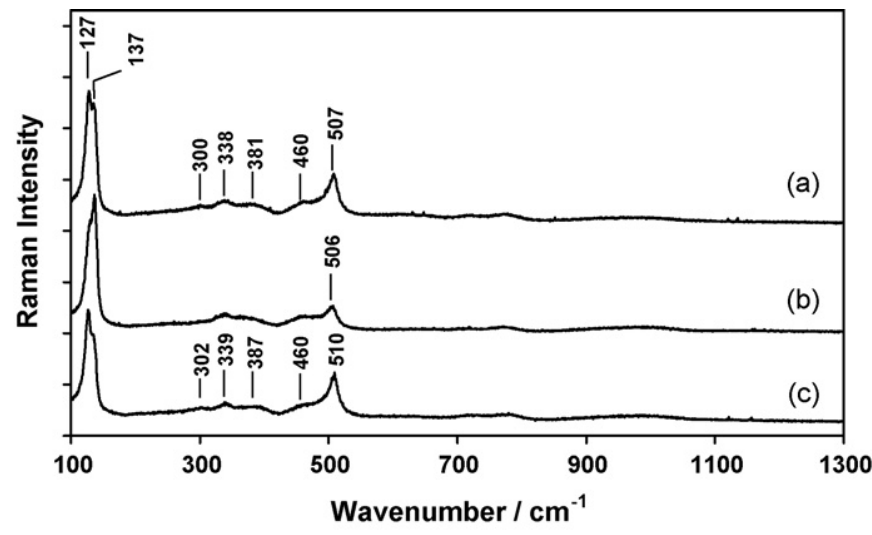

Fig. 2. All three spectra were collected from the yellow background on the tile using $514.5 \mathrm{~nm}$ radiation (5-20 $\mathrm{mW}$ laser power as measured at the source), (a) bright yellow, (b) orange yellow and (c) brownish yellow. Similar results are obtained with $568.2 \mathrm{~nm}$ radiation with $3 \mathrm{~mW}$ laser power as measured at the source.

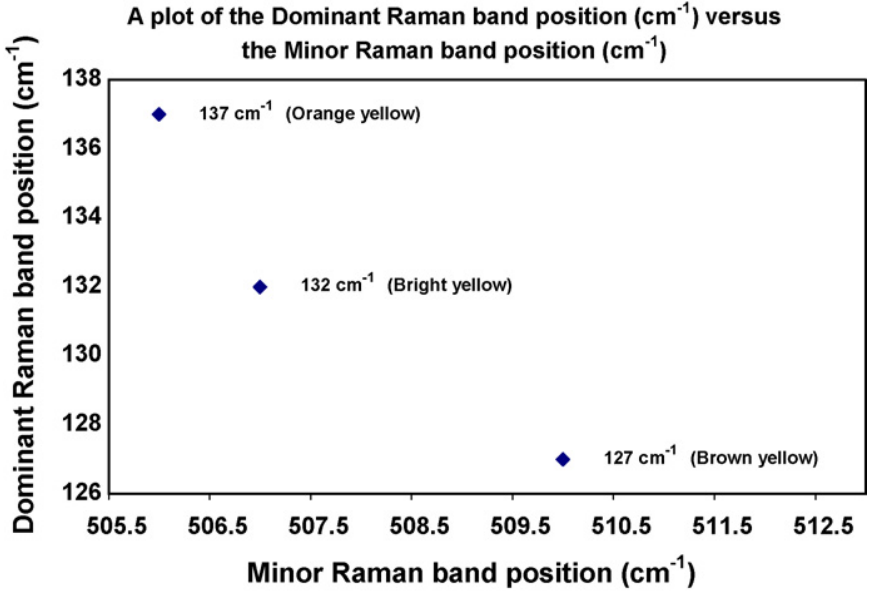

Fig. 3. A plot of the wavenumbers of the dominant Raman band found at ca $127-145 \mathrm{~cm}^{-1}$ (vertical axis) versus the shift of the minor Raman band found at ca. $506-510 \mathrm{~cm}^{-1}$ is shown. The bright-yellow colour corresponds to a doublet of the 137 and $127 \mathrm{~cm}^{-1}$ of Raman bands from which a single band centered at $132 \mathrm{~cm}^{-1}$ sometimes appear.

the two Raman bands at 127 and $137 \mathrm{~cm}^{-1}$. On the other hand, the reference compound prepared with the ratio $\mathrm{Sn}: \mathrm{Sb}=1: 1$ only shows a low wavenumber $\mathrm{Pb}-\mathrm{O}$ vibration at $127 \mathrm{~cm}^{-1}$, indicating that the dominant Raman band for the ternary $(\mathrm{Pb}-\mathrm{Sn}-\mathrm{Sb})$ pyrochlore system shifts to lower wavenumbers $\left(127 \mathrm{~cm}^{-1}\right)$. It is conceivable that the Raman band centrered at $132 \mathrm{~cm}^{-1}$ observed in other studies [30] could be a combination of the two bands (127 and $137 \mathrm{~cm}^{-1}$ ) appearing as a single band centered at $132 \mathrm{~cm}^{-1}$ (see Fig. 3 ) or it may be emanate from different $\mathrm{Sn}$ :Sb ratios. Additional bands appearing at 210 and $655 \mathrm{~cm}^{-1}$ in Fig. 4(e) have been confirmed by XRD and Raman spectroscopy to emanate from small amounts of Rosiaite $\left(\mathrm{PbSb}_{2} \mathrm{O}_{6}\right)$ present.

\subsubsection{Redish-brown pigment}

The redish-brown pigment provides a decorative transition from the yellow to the brown-black and then to the white background (Plate 1 (number 2)). The dominant Raman band on this pigment remains at ca. $139-140 \mathrm{~cm}^{-1}$ (Fig. 5(a)). Unlike the yellow pigment, the redish-brown pigment appear to be homogeneous with regard to colour and indeed only one shade of redish-brown (yellowish)

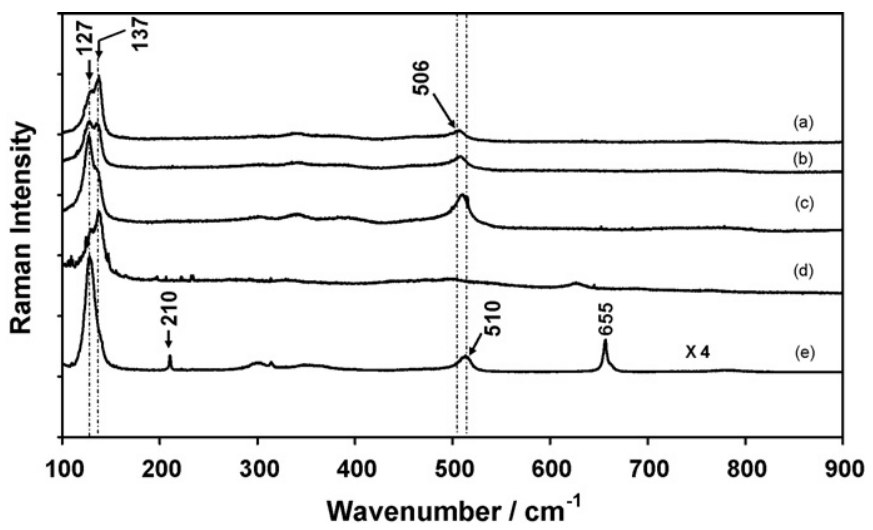

Fig. 4. The spectra of the yellow pigment on the tile in $(\mathrm{a}-\mathrm{c})$ while the synthesized reference pyrochlore system $\left(\mathrm{Pb}_{2} \mathrm{SnSbO}_{6.5}\right)$ with traces of rosiaite $\left(\mathrm{PbSb}_{2} \mathrm{O}_{6}\right)$, with Raman bands at 210 and $655 \mathrm{~cm}^{-1}$ (confirmed by XRD) is shown in (e). The two dominant Raman bands at 127 and $510 \mathrm{~cm}^{-1}$ are in excellent agreement with the tile spectra and leads us to the conclusion that the dominant Raman band for the ternary $\mathrm{Pb}-\mathrm{Sn}-\mathrm{Sb}$ occurs at $127 \mathrm{~cm}^{-1}$ and that the spectra shown in $(\mathrm{a}-\mathrm{c})$ comes from mixtures of compounds. (d) The ternary compound that is deficient in Sb. 


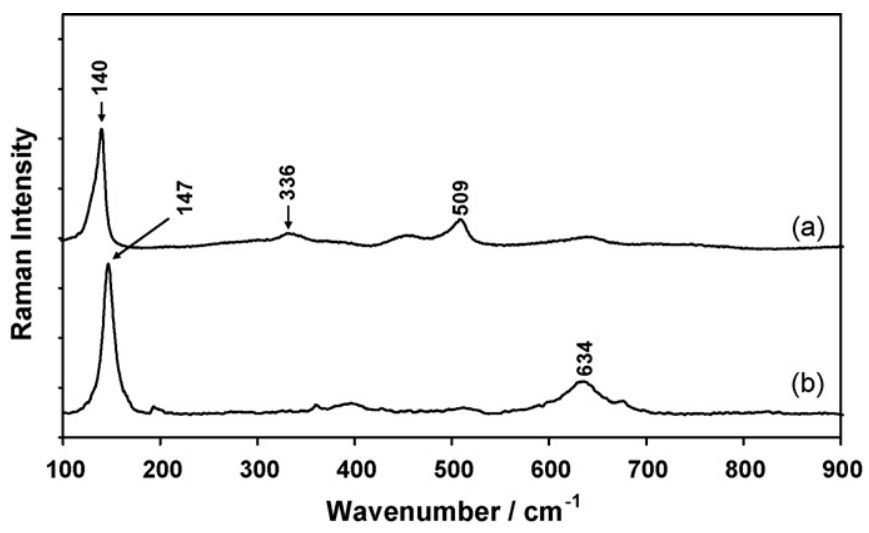

Fig. 5. The spectrum shown in (a) identifies Naples yellow $\left(\mathrm{Pb}_{2} \mathrm{Sb}_{2} \mathrm{O}_{7}\right)$ with a strong Raman band at $140 \mathrm{~cm}^{-1}$ while (b) is identified as lead (II) stannate $\left(\mathrm{Pb}_{2} \mathrm{SnO}_{4}\right)$.

was discernable on this pigment under the microscope. The band at $633 \mathrm{~cm}^{-1}$ in this spectrum could be attributed to $\mathrm{SnO}_{2}$ in the Sn-based glaze. Another difference with the yellow pigment is that the $140 \mathrm{~cm}^{-1}$ Raman band is associated with the higher wavenumber $510 \mathrm{~cm}^{-1}$ band rather than the lower $506 \mathrm{~cm}^{-1}$ Raman band as observed for the yellow pigment on the tile, indicating a structural difference with the bright yellow pigment. The EDX results of this pigment on the tile confirms the presence of lead and antimony in ratios $(\mathrm{Pb}: \mathrm{Sb})$ that are consistent with Naples yellow $\left(\mathrm{Pb}_{2} \mathrm{Sb}_{2} \mathrm{O}_{7}\right)$. The Raman spectrum also identifies this pigment to be Naples yellow with a strong Raman band at $140 \mathrm{~cm}^{-1}$ and a second most intense band at $510 \mathrm{~cm}^{-1}$ [32].

\subsubsection{Brown-black pigment}

The brown-black pigment on the tile shows a Raman spectrum similar to the yellow/redish-brown pigments discussed above with a strong (DB) Raman band at $147 \mathrm{~cm}^{-1}$ and a weak Raman band at $509 \mathrm{~cm}^{-1}$ (Fig. 5(b)). EDX data of this pigment on the tile also show the presence of lead and tin in the ratio $\mathrm{Pb}: \mathrm{Sn}=2: 1$ consistent with lead(II) stannate $\left(\mathrm{Pb}_{2} \mathrm{SnO}_{4}\right)$ and the results were thus deemed to be sufficient to identify this pigment as lead(II) stannate.

\subsubsection{Blue pigment}

The blue coloured background on this tile has been repeatedly probed at various surface locations and different laser powers using the depth profiling method and none of the obtained spectra could be associated with the blue pigment. Fig. 6(a-f) shows glaze depth profile spectra showing $\mathrm{SnO}_{2}$ and $\alpha$-quartz at vari-

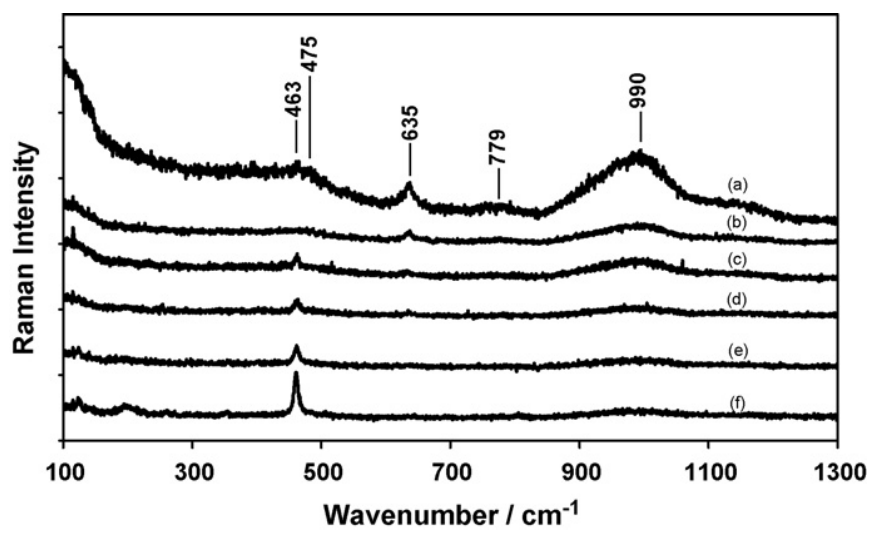

Fig. 6. The glaze depth profile spectra on the blue background collected at different depths (a) surface $(0 \mu \mathrm{m})$, (b) $4 \mu \mathrm{m}$, (c) $12 \mu \mathrm{m}$, (d) $20 \mu \mathrm{m}$, (e) $28 \mu \mathrm{m}$ and (f) $36 \mu \mathrm{m}$ on the same vertical position using a $514.5 \mathrm{~nm}$ radiation failed to conclusively identify the blue colour as cobalt blue.

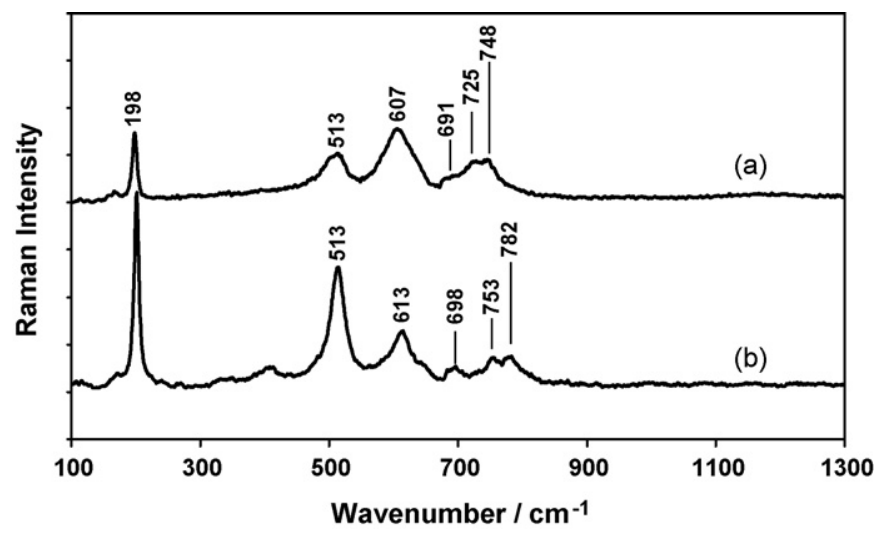

Fig. 7. The blue pigment (a) found on crevices on the tile is compared to the blue pigment synthesized in this laboratory (b). This confirms that the blue colour on the tile is due to cobalt aluminium oxide $\left(\mathrm{CoAl}_{2} \mathrm{O}_{4}\right)$.

ous glaze depths towards the glaze/body interface. The blue colour may be the result of desolved Co ions in the glaze [33]. It may also be the result of a small Raman cross section for the pigment in this glaze. Minimum differential Raman cross-sections are in the order of $(\mathrm{d} \sigma / \mathrm{d} \Omega) \approx 10^{-31}-10^{-28} \mathrm{~cm}^{2} \mathrm{sr}^{-1}$ [34]. Although the sampled volume at the focal point is in orders $<1 \mu \mathrm{m}^{3}$, if the pigment concentration in the glaze of this tile is in orders of magnitude comparable with molecular monolayers within the sampled volume, the detection of the pigment will be out of reach without any additional forms of Raman signal enhancements such as Surface Enhanced Raman Spectroscopy (SERS) or resonance effects. Plate 3(a) shows the optical microphotograph taken from the surface/glaze/body cross section on the blue background. The blue pigment appears to be dispersed throughout the glaze towards the surface. Isolated but larger blue pigment crystallites in crevices on the surface where found and a clear Raman spectrum could be obtained by focusing directly on these. Fig. 7(a-b) shows the identified blue pigment as cobalt aluminium oxide or Cobalt blue $\left(\mathrm{CoAl}_{2} \mathrm{O}_{4}\right)$. Fig. 7(a) is the spectrum obtained from the tile while Fig. 7(b) is that of the synthesized pigment.

\subsubsection{White pigment}

Among the various pigments that were used in the decoration of the Citadel tile, the white pigment appears to be the dominant material providing the colour as it also forms the bulk of the glaze. Fig. 8(a) shows a representative Raman spectrum collected from the white pigment that has been identified as cassiterite $\left(\mathrm{SnO}_{2}\right)$ [35] and Fig. 8(b) is that of the reference $\mathrm{SnO}_{2}$ (Merck). The depth profiling method reveals that during the manufacturing of the tile, the white material was used as a foundation on which all other colours were subsequently spread. This is consistent with the historical evidence of the use of a mixture of $\mathrm{SnO}_{2}$ and $\alpha$-quartz as opacifiers [36]. Glaze depth profile spectra from the white background on the tile are shown in Fig. 9(a-e). Fig. 9(a) shows a representative spectrum of the white surface with two $\left(635\right.$ and $\left.779 \mathrm{~cm}^{-1}\right)$ of the three Raman bands associated with the cassiterite structure $\left(\mathrm{SnO}_{2}\right)$. The cassiterite structure is tetragonal with 2 molecules per unit cell and belongs to the $D_{2 \mathrm{~h}}^{14}\left(\mathrm{P}_{4 / \mathrm{mnm}}\right)$ space group [37,38]. From group theory considerations, there are four Raman active modes $\left(A_{1 \mathrm{~g}}, B_{1 \mathrm{~g}}\right.$, $B_{2 \mathrm{~g}}$ and $E_{\mathrm{g}}$ ) [38]. The two observed Raman bands in Fig. 9(a) may be assigned as $635 \mathrm{~cm}^{-1}\left(A_{1 \mathrm{~g}}\right)$ and $799 \mathrm{~cm}^{-1}\left(B_{2 \mathrm{~g}}\right)$ consistent with literature assignments [37-40] for cassiterite. Raman measurements in this study prove conclusively that $\mathrm{SnO}_{2}$ was deliberately used as the dominant component of the white glaze, in admixture with $\alpha$-quartz. The glaze on this tile is similar to "faiences", ceramic where Sn-containing glazes are used [35]. It is also known that 


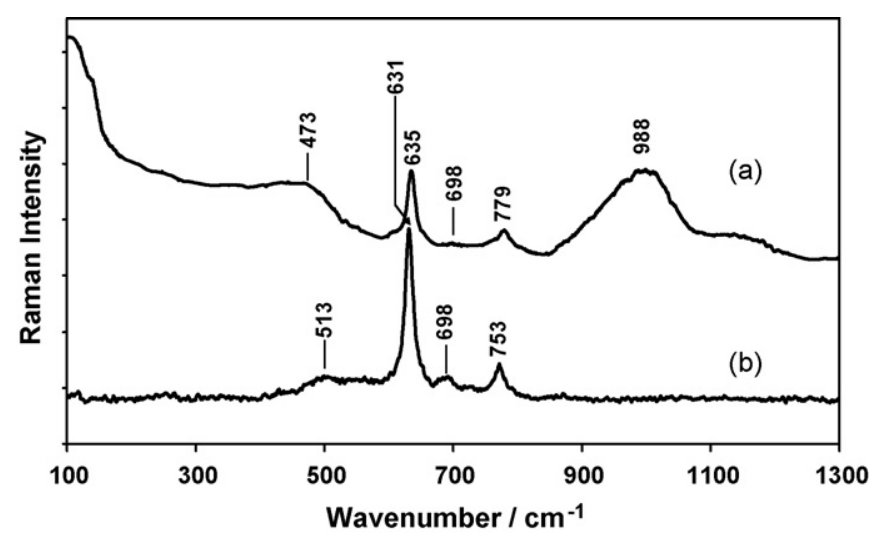

Fig. 8. The spectrum in (a) from the white background on the Citadel tile as it is compared to the reference spectrum of $\mathrm{SnO}_{2}$ (Merck) shown in (b). The three identified Raman bands $\left(635,698\right.$ and $\left.779 \mathrm{~cm}^{-1}\right)$ confirm that the white material on the shard is cassiterite. Broad bands around 500 and $1000 \mathrm{~cm}^{-1}$ on the shard spectrum could be attributed to silicates that are present in the glaze.

$\mathrm{SnO}_{2}$ was used as opacifier in ceramic materials during the period ca. 1510-1530 in Iznik (former Nicaea) [36]. Since the Citadel of Algiers was constructed in 1516, it is conceivable that this technology, if not developed locally by the Algerians of the day may still have been available to the builders of the Citadel of Algiers.

While the bulk of the glaze spectra show this form of $\mathrm{SnO}_{2}$, the specific vertical position chosen here (Fig. 9) also show $\alpha$-quartz $\left(464 \mathrm{~cm}^{-1}\left(A_{1 \mathrm{~g}}\right)\right)$ and amorphous carbon (1350 and $\left.1600 \mathrm{~cm}^{-1}\right)$ [41,42] at a depth of about $50 \mu \mathrm{m}$ into the glaze. This profiling method is useful in establishing for example that indeed the amorphous carbon is not on the glaze surface but inside the glaze towards the glaze/body interface and could very well be a trace contaminant that was introduced at the time of manufacture of the tile. Careful analysis of the body directly on the broken edge has established the presence of amorphous carbon in the tile body as discussed below under the heading, amorphous carbon.

\subsubsection{Tile body analysis}

3.2.6.1. Hematite, maghemite and magnetite. The thick (ca. $12 \mathrm{~mm}$ ) body of the Citadel tile is composed macroscopically of red/brown material resembling red iron oxide. Under the microscope however, particles of various colours ranging from black, red/brown and white are observed. Fig. 10(a) shows a representative Raman spectrum collected from one of the red/brown particles and was

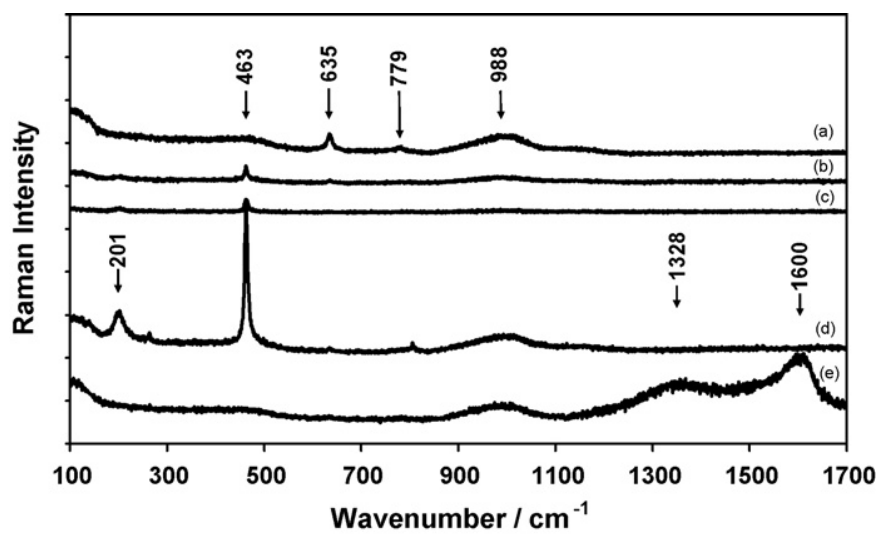

Fig. 9. The depth profile spectra of the top $50 \mu \mathrm{m}$ generated on the white background of the tile showing (a) cassiterite on the surface at $0 \mu \mathrm{m}$, (b-d) $\alpha$-quartz $(8-24 \mu \mathrm{m})$, and (e) amorphous carbon at $30 \mu \mathrm{m}$ in the interior of the white glaze (see also Plate $2(\mathrm{~b})$ ).

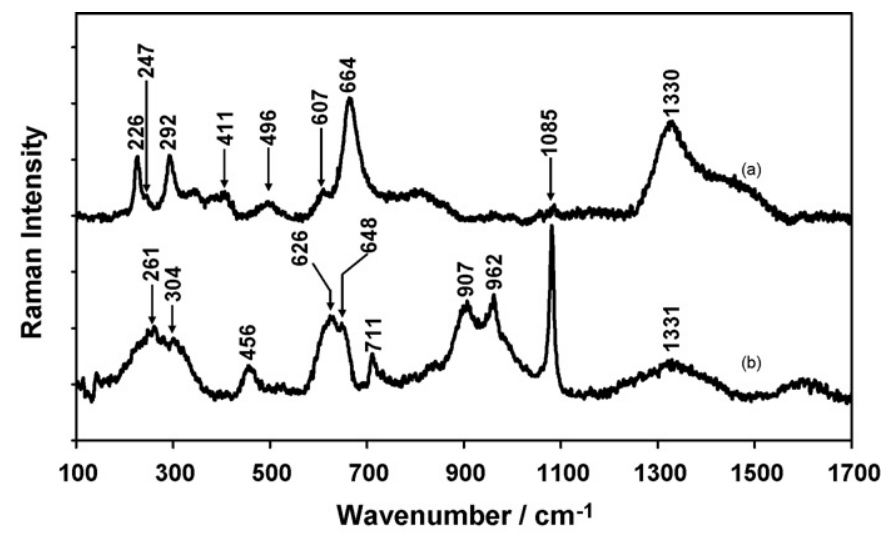

Fig. 10. The two spectra show the presence of (a) hematite $\left(\alpha-\mathrm{Fe}_{2} \mathrm{O}_{3}\right)$, (b) maghemite $\left(\gamma-\mathrm{Fe}_{2} \mathrm{O}_{3}\right)$ and (c) magnetite $\left(\mathrm{Fe}_{3} \mathrm{O}_{4}\right)$. (b) Raman bands at 711 and $1085 \mathrm{~cm}^{-1}$ that are attributed to calcite, the most stable of the three crystal phases of calcium carbonate $\left(\mathrm{CaCO}_{3}\right)$.

identified as hematite $\left(\alpha-\mathrm{Fe}_{2} \mathrm{O}_{3}\right)$. Six of the seven hematite Raman active bands that are predicted by group theory $\left(2 A_{1 \mathrm{~g}}+5 E_{\mathrm{g}}\right)[43-46]$ at $226 \mathrm{~cm}^{-1}\left(A_{1 \mathrm{~g}}\right), 247 \mathrm{~cm}^{-1}\left(E_{\mathrm{g}}\right), 292 \mathrm{~cm}^{-1}\left(E_{\mathrm{g}}\right), 411 \mathrm{~cm}^{-1}\left(E_{\mathrm{g}}\right)$, $607 \mathrm{~cm}^{-1}\left(E_{\mathrm{g}}\right), 496 \mathrm{~cm}^{-1}\left(A_{1 \mathrm{~g}}\right)$, and the hematite's two magnon scattering band at $1330 \mathrm{~cm}^{-1}$ are observed (Fig. 10(a)). On closer examination the Raman band $298 \mathrm{~cm}^{-1}$ is observed as a shoulder on the $292 \mathrm{~cm}^{-1}$ band, consistent with what has been observed elsewhere $[44,45]$. Hematite is often identified on a wide range of artifacts from all over the world as a result of its long history of use. For instance this form of iron oxide has been identified on archaeological pottery shards from sites in south Africa and a brown tea pot from China [47], in materials used for jewellery and mosaics excavated in El Djem (Tunisia) [48] and ochre samples excavated from neolithic sites at Catalhoyuk (Turkey) and Clearwell caves (UK) [46] as testimony to its long history of use at various localities around the world. It is generally one the most common of the red/brown inorganic pigments used especially during the time of construction of the Citadel of Algiers in 1516. This compound could also be part of the tile purely as a result of the use of earthenware material as the body of the tile. In addition to $\alpha-\mathrm{Fe}_{2} \mathrm{O}_{3}$, maghemite $\left(\gamma-\mathrm{Fe}_{2} \mathrm{O}_{3}\right)$ and magnetite $\left(\mathrm{Fe}_{3} \mathrm{O}_{4}\right)$ are also detected in the tile body as shown in Fig. 10(a) and (b). Maghemite is usually identified by broad features around 350,500 and $700 \mathrm{~cm}^{-1}$ as is evident in the Raman spectrum (Fig. 10(b)). The band at $664 \mathrm{~cm}^{-1}$ in Fig. 10(a) is attributed to magnetite [36].

3.2.6.2. Quartz. Fig. 11(a) and (b) shows the Raman spectra of glassy silica and $\alpha$-quartz (trigonal $\mathrm{SiO}_{2}$ with a strong $A_{1 \mathrm{~g}}$ band at $463 \mathrm{~cm}^{-1}$ ) as identified on the body of the Citadel tile. These phases appeared as white crystalline materials embedded in the red/brown body of the tile when viewed through the microscope.

3.2.6.3. Calcite. Among the three crystal phases of calcium carbonate (Calcite, aragonite and Vaterite), Calcite, the thermodynamically most stable phase, is detected in the body of the Citadel tile as evidenced by two Raman bands at $1085 \mathrm{~cm}^{-1}\left(A_{1 \mathrm{~g}}\right)$ and $711 \mathrm{~cm}^{-1}\left(E_{\mathrm{g}}\right)$ (Fig. 10(b)) [49,50]. Although the three phases have a strong Raman band at ca. $1085 \mathrm{~cm}^{-1}$, the additional band at $711 \mathrm{~cm}^{-1}$ was sufficient to distinguish this phase as calcite. Aragonite and vaterite have equivalent Raman bands at 700 and $750 \mathrm{~cm}^{-1}$, respectively [49].

3.2.6.4. Amorphous carbon. The doublet at ca. 1328 and $1600 \mathrm{~cm}^{-1}$ in Fig. 11(c) has been attributed to traces of amorphous carbon in the body of the tile sample and are due to D and G Raman bands of carbon, respectively $[39,40]$. The carbon traces were observed 


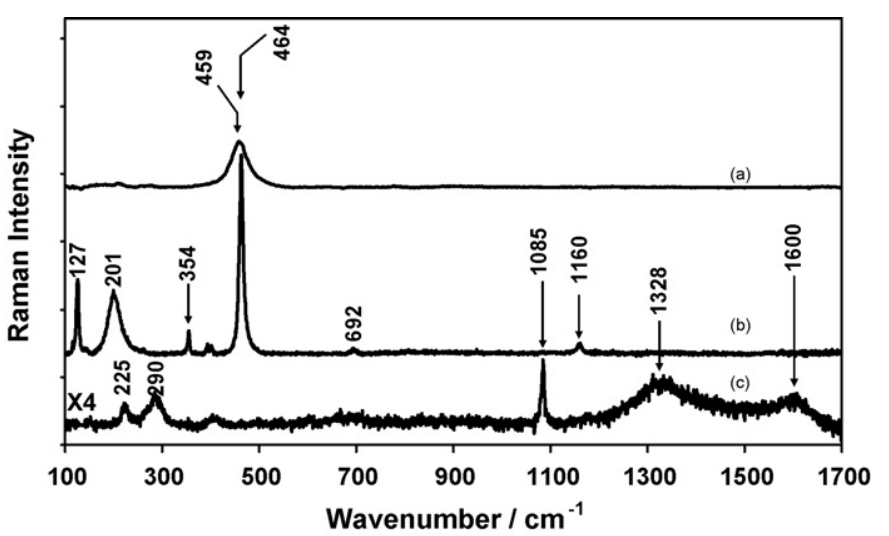

Fig. 11. In this figure, we identify glassy silica with a slightly broad Raman band at $459 \mathrm{~cm}^{-1}$ (a), $\alpha$-quartz $\left(127,201,354\right.$ and $464 \mathrm{~cm}^{-1}$ ), amorphous carbon (1328 and $\left.1600 \mathrm{~cm}^{-1}\right)$ and calcium carbonate $\left(1085 \mathrm{~cm}^{-1}\right)$ in the body spectra. Raman bands at 225 and $290 \mathrm{~cm}^{-1}$ (c) could be attributed to the presence of $\alpha-\mathrm{Fe}_{2} \mathrm{O}_{3}$ that has already been shown to comprise the bulk of the body.

whenever black particles where specifically focused upon with the laser beam on the exposed body surface. However, amorphous carbon was also detected through the glaze at depths exceeding $60 \mu \mathrm{m}$ by the glaze depth profiling method (Fig. 9(e)). This form of carbon was not detected on the surface of the glaze. In some cases the amorphous carbon was found mixed with calcite $\left(\mathrm{CaCO}_{3}\right)$ (Fig. $11(\mathrm{c})$ ). Although the absence of a phosphate Raman band ca. $960 \mathrm{~cm}^{-1}$ may suggests that the black pigment detected here is most probably similar to lamp black rather than ivory black $[16,51]$, the absence of the phosphate band should not be used to exclude animal remains as a possible source as these samples often fail to show this band $[51,52]$.

\section{Conclusion}

The use of Raman spectroscopy in the study of the Citadel tile produced a large body of information that included the identification of a rich combination of pigments $\left(\mathrm{Pb}_{2} \mathrm{Sb}_{2} \mathrm{O}_{7}, \mathrm{~Pb}_{2} \mathrm{SnSbO}_{6.5}\right.$ and $\mathrm{Pb}_{2} \mathrm{SnO}_{4}$ ) whose positive identification could assist in the restoration and preservation of the Citadel as well as contribute to discussions on the pre-colonial trade relations within the Mediterranean region. The brownish yellow colour is associated with the ternary pigment $\left(\mathrm{Pb}_{2} \mathrm{SnSbO}_{6.5}\right)$ rather than the bright yellow normally used by the Italian painters of the time. The method allowed for reliable identification of the various pigments (redish-brown, brown-black, blue, white and yellow) in addition to glaze type confirmation. The pigments were found spread as a surface layer on a Tin oxide-based glaze rather than as underglaze pigments or mixed in with the glaze thus giving a rich visual effect to the tile. Quartz was detected throughout the otherwise cassiterite $\left(\mathrm{SnO}_{2}\right)$ dominated glaze. The implication of the deliberate use of cassiterite as an opacifier is consistent with the use of this technology in Iznik ca. 1510-1530, a period straddling that of the construction of the Citadel of Algiers in 1516. Calcite, amorphous carbon, hematite, maghemite, magnetite and $\alpha$-quartz are also identified in the body of the citadel tile. Raman spectroscopy, in conjunction with other techniques (XRD and EDX) is again shown to be of immense value in the study of pigments on historical artifacts and the results could easily be used for purposes of restoration and conservation. The use of the glaze depth profiling method also allows for accurate characterization of the glaze leading to more reliable determinations of the order in which materials were applied to the tile at the time of manufacture and may also be used to study underglaze pigments on intact ceramic artifacts.

\section{Acknowledgements}

The University of Pretoria, The National Research Foundation (Financial) and an anonymous donor for supplying the tile from the Citadel of Algiers are gratefully acknowledged.

\section{References}

1] L. Burgio, R.J.H. Clark, K. Theodoraki, Spectrochim. Acta Part A 59 (2003) 2371.

[2] R.J.H. Clark, C. R. Chimie 5 (2002) 7.

[3] L. Burgio, R.J.H. Clark, J. Raman Spectrosc. 31 (2000) 395

[4] J. Zuo, C. Xu, C. Wang, Z. Yushi, J. Raman Spectrosc. 30 (1999) 1053.

[5] Ph Colomban, G. Sagon, X. Faurel, J. Raman Spectrosc. 32 (2001) 351.

[6] D. De Waal, J. Raman Spectrosc. 35 (2004) 646.

[7] H.G.M. Edwards, C. Brooke, J.K.F. Tait, J. Raman Spectrosc. 28 (1997) 95.

[8] H.G.M. Edwards, Microsc. Anal. 59 (1997) 5.

[9] H.G.M. Edwards, D.W. Farwell, F Rull Pérez, S. Jorge Villar, Appl. Spectrosc. 53 (11) (1999) 1436.

[10] M. Breitman, S. Ruiz-Moreno, R. Pérez-Pueyo, J. Cultural Heritage 4 (2003) 314s.

[11] H.G.M. Edwards, J.K.F. Tait, J. Raman Spectrosc. 30 (1999) 429.

[12] D. Yi-Lin, Y. Qun, C.-Z. Li, Guang Pu 24 (2004) 823.

[13] R.J.H. Clark, L.M. Curri, J. Mol. Struct. 440 (1998) 105

[14] H.G.M. Edwards, J. Mol. Struct. 661 (2003) 271

[15] L.D. Kock, D. De Waal, J. Raman Spectrosc. 38 (2007) 1480.

[16] http://www.chem.ucl.ac.uk/resources/raman, accessed 15 May 2008.

[17] http://minerals.caltech.edu/FILES/raman/, accessed 15 May 2008.

[18] http://rruff.geo.arizona.edu/rruff/, accessed 17 May 2007.

[19] K. Castro, M. Pérez-Alonso, M.D. Rodríguez-Laso, J.M. Madariaga, Spectrochim. Acta Part A 60 (2004) 2919.

[20] S. Bruni, F. Cariati, L. Consolandi, A. Galli, V. Guglielmi, N. Ludwig, M. Milazzo, Appl. Spectrosc. 56 (2002) 827.

[21] D. De Waal, Asian Chem. Lett. 8 (2004) 57.

[22] Ph. Colomban, Orient. Ceram. Soc. Fr. (SFECO) Lett. 7 (2003) 7.

[23] R.J.H. Clark, L. Cridland, B.M. Kariuki, K.D.M. Harris, R.J. Withnal, J. Chem. Soc. Dalton Trans. (1995) 2577.

[24] L. Burgio, R.J.H. Clark, S. Firth, Analyst 126 (2001) 222.

[25] D.A. Ciamartan, R.J.H. Clark, L.J. McDonald, M. Odlyha, J. Chem. Soc., Dalton Trans. (1996) 3639.

[26] Labspec, version 3.01, Distributed by Dilor SA \& Université de Reims, France, 2004.

[27] S. Verryn, Details of XRD Procedure Used at the University of Pretoria, XRD Laboratory, Personal Written Communication, University of Pretoria, Pretoria, 2007.

[28] A. Roy, B.H. Berrie, in: A. Roy, P. Smith (Eds.), A New Lead-based Yellow in the Seventeenth Century Painting Techniques: History, Materials and Studio Practice, The International Institute for Conservation of Historic and Artistic Works, London, 1998, p. 160

[29] S. Ruiz-Moreno, R. Perez-Pueyo, A. Gabaldon, M.-J. Soneira, C. Sandalinas, J. Cultural Heritage 4 (2003) 309s;

See also C. Sandalinas, S. Ruiz-Moreno, Stud. Conserv. 49 (2004) 41.

[30] C. Sandalinas, S. Ruiz-Moreno, A. Lopez-Gill, J. Miralles, J. Raman Spectrosc. 37 (2006) 1146.

[31] C. Cascales, J.A. Alonso, I. Rasines, J. Mater. Sci. Lett. 5 (1986) 675.

[32] H.G.M. Edwards, J. Raman Spectrosc. 35 (2004) 656.

[33] Ph Colomban, R. De Laveaucoupet, V. Milande, J. Raman Spectrosc. 36 (2005) 857.

[34] B. Pettinger, B. Ren, G. Picardi, R. Schuster, Ertl. G. 36 (2005) 541.

[35] Ph Colomban, C. Truong, J. Raman Spectrosc. 35 (2004) 195.

[36] Ph Colomban, V. Milande, L. Le Bihan, J. Raman Spectrosc. 35 (2004) 527

[37] R.S. Katiyar, R.S. Krishnan, Phys. Lett. 25A (1967) 525.

[38] M. Ocaña, C.J. Serna, J.V. Garcia-Ramos, E. Matijević, Solid State Ionics 63 (1993) 170.

[39] J.F. Mammone, M. Nicol, S.K. Sharma, J. Phys. Chem. Solids 42 (1981) 379

[40] M. Ristić, M. Ivanda, S. Popović, S. Musić, J. Non-Cryst. Solids 303 (2002) 270.

[41] Y. Kawashima, G. Katagiri, Phys. Rev. B 14 (1995) 52

[42] F. Tuinstra, J.L. Koenig, J. Chem. Phys. 53 (1970) 1126

[43] M.A. Legodi, D. De Waal, Spectrochim. Acta Part A. 66 (2007) 135.

[44] L.A. De Faria, S.V. Silva, M.T. De Oliviera, J. Raman Spectrosc. 28 (1997) 873.

[45] L. Burgio, R.J.H. Clark, Spectrochim. Acta 57 (2001) 1491.

[46] J.L. Mortimore, L.-J.R. Marshall, M.J. Almond, P. Hollins, W. Matthews, Spectrochim. Acta 60A (2004) 1179.

[47] M.A. Legodi, D. De Waal, Cryst. Eng. 6 (2003) 287.

[48] Ph Colomban, G. March, L. Mazerolles, T. Karmous, N. Ayed, A. Ennabli, H. Slim, J. Raman Spectrosc. 34 (2003) 205.

[49] J.C. Orlianges, C. Champeaux, A. Catherinot, Th. Merle, B. Angleraud, Thin Solid Films 453 (2004) 285

[50] K. Nakamoto, Infrared and Raman spectra of inorganic and coordination compounds, in: Part A: Theory and Applications in Inorganic Chemistry, John Wiley \& Sons, Ltd., New York, 1997, pp. 138-139.

[51] H.G.M. Edwards, D.W. Farwell, E.M. Newton, F. Rull Perez, S. Jorge Villar, J. Raman Spectrosc. 31 (2000) 407

[52] I.M. Bell, R.J.H. Clark, P.J. Gibbs, Spectrochim. Acta Part A 53 (1997) 2159. 